\title{
Erratum to: Non-uniform shrinkage of multiple-walled carbon nanotubes under in situ electron beam irradiation
}

\author{
Lunxiong $\mathrm{Li}^{1,2} \cdot$ Jiangbin $\mathrm{Su}^{1,3} \cdot$ Xianfang $\mathrm{Zhu}^{1}$
}

Published online: 7 June 2017

(C) Springer-Verlag GmbH Germany 2017

\section{Erratum to: Appl Phys A (2016) 122:912 DOI 10.1007/s00339-016-0418-8}

The original version of this article unfortunately contained mistakes.

The corresponding author was incorrect. The correct name is Xianfang Zhu.

The affiliations of the first author were in the wrong order; the correct order is

${ }^{1}$ China-Australia Joint Laboratory for Functional Nanomaterials and Physics Department, Xiamen University, Xiamen 361005, China
${ }^{2}$ Brain Science Institute, South China Normal University, Guangzhou 510631, China.

The correct acknowledgement is given here:

Acknowledgements This work was supported by the NSFC projects under Grant Nos. 11574255, 61404052, 60776007 and 11074207 and China Ministry of Education Special Scientific Research Fund for Doctor Discipline of Institution of Higher of Learning under Grant No. 20100121110023.
The online version of the original article can be found under doi:10.1007/s00339-016-0418-8.

\section{Xianfang Zhu}

zhux@xmu.edu.cn

1 China-Australia Joint Laboratory for Functional Nanomaterials and Physics Department, Xiamen University, Xiamen 361005, China

2 Brain Science Institute, South China Normal University, Guangzhou 510631, China

3 School of Mathematics and Physics, Chang Zhou University, Changzhou 213164, China 